\title{
Potencias de la ficción: cine y literatura en Valencio Xavier
}

\author{
Powers of fiction: film and literature in Valencio Xavier \\ Potências da ficção: cinema e literatura em Valencio Xavier
}

\section{Mario Cámara}

CONICET/UNIVERSIDAD DE BUENOS AIRES, ARGENTINA

Doctor en Letras (UBA). Profesor de Literatura brasileña en la

Universidad de Buenos Aires e investigador en el Consejo Nacional de Investigaciones Científicas (CONICET). Ha publicado los libros El caso Torquato Neto, diversos modos de ser vampiro en Brasil en los años setenta (Lumen editor, 2011); Cuerpos paganos, usos y efectos en la cultura brasileña 1960-1980 (Santiago Arcos Editor, 2011); A máquina performática (Rocco, 2017), en colaboración con Gonzalo Aguilar, y Restos épicos. Relatos e imágenes en el cambio de época (Livraria, 2017). Entre sus últimos artículos se cuentan: "Néstor Perlongher, un destino brasileño" (Revista Hispamérica, 2016) y "La palabra muda. Espectros y ruinas en Joao Gilberto Noll" (RECIAL, 2015). Correo electrónico: mario_camara@hotmail.com

\footnotetext{
Artículo de investigación

Este texto forma parte de un proyecto de investigación UBA/CONICET, en desarrollo, en torno a las relaciones entre visualidad y literatura en Latinoamérica.

Documento accesible en línea desde la siguiente dirección: http://revistas.javeriana.edu.co doi:10.11144/Javeriana.cl22-44.pfcl
} 


\section{Resumen}

El presente artículo se propone abordar parte de la producción cinematográfica y literaria del autor brasileño Valencio Xavier, con el objetivo de encontrar zonas de contacto, reflexionar en torno a la figura de autor que emerge en ese contacto y proponer una serie de figuras que articulen y subsuman cine y literatura en una categoría más abarcativa.

Palabras clave: cine y literatura; préstamos; diálogos; figura de autor; ficción

\section{Abstract}

This article intends to think a part of the cinematographic and literary production of the brazilian author Valencio Xavier with the objective of finding contact areas, to reflect on the figure of author that emerges in that contact and to propose a series of figures that articulate and subsume his cinema and her literature in a more encompassing category.

Keywords: Cinema and literature; loans; dialogues; figure of author; fiction

\section{Resumo}

O presente artigo propõe-se abordar parte da produção cinematográfica e literária do autor brasileiro Valencio Xavier, objetivando encontrar áreas de contato, refletir em torno da figura de autor que emerge nesse contato e propor uma série de figuras que articulem e subsomem cinema e literatura em uma categoria mais abrangente.

Palavras-chave: cinema $\mathrm{e}$ literatura; empréstimos; diálogos; figura de autor; ficção

RECIBIDO: 28 DE FEBRERO DE 2017. ACEPTADO: 1 DE NOVIEMBRE DE 2017. DISPONIBLE EN LÍNEA: 28 DE DICIEMBRE DE 2018

\section{Cómo citar este artículo:}

Cámara, Mario. "Potencias de la ficción: cine y literatura en Valencio Xavier". Cuadernos

de Literatura 22.44 (2018): 63-76. https://doi.org/10.11144/Javeriana.c122-44.pfcl 
¿Cómo LeEr a un escritor que hace cine o a un cineasta que hace literatura? ¿Qué tipo de vínculos, si los hubiera, establecer entre su literatura y su cine? La cultura brasileña es rica en este tipo de tránsitos, probablemente amparada en una tradición de cruces y colaboraciones que nacieron con la Semana de Arte Moderno, cuando escritores, músicos y artistas visuales fundaron la vanguardia brasileña. En el ámbito del cine y la literatura, unos pocos ejemplos relevantes alcanzan para pensar en la potencia de esos pasajes: el músico Caetano Veloso filmó en los ochenta $O$ Cinema falado, el cineasta Glauber Rocha escribió en los setenta la novela Riverão sussuarana, mientras que José Agrippino de Paula, autor de las novelas Lugar público y PanAmérica también es el autor del largo Hitler III Mundo y numerosos cortos. Pero probablemente sea Valencio Xavier (1933-2008) quien ocupe un sitio en donde estos cruces se hayan dado con mayor continuidad en el tiempo y mayor complejidad. En primer lugar, debido a una trayectoria que incluyó un intenso trabajo televisivo, que abarcó tanto la producción como la escritura de guiones para telenovelas. Valencio Xavier fue, además, fundador de la Cinemateca de Curitiba, ${ }^{1}$ y estrenó su primera película, un corto de quince minutos sobre el asesinato de una prostituta titulado $A$ visita do velho senhor, en $1976 .{ }^{2}$ Casi al mismo tiempo, un año antes, publicaba su primer texto, un libro en colaboración con el artista visual Poty Lazzarotto, Curitiba de nós. En 1979 Valencio filma su segundo corto, Caro signore Fellini (Carta a Fellini), ${ }^{3}$ que tiene como pretexto invitar al cineasta italiano Federico Fellini a la ciudad de Curitiba. La propuesta narrativa y visual de este corto articula una estética circense con registros documentales. Al año siguiente, a pedido del Canal 12, sucursal de la Red Globo, rodará O monge da Lapa, ${ }^{4}$ un mediometraje que narra la trayectoria del monje João Maria y de sus seguidores. Una vez más, Xavier apela a la estética circense, pero no solo como forma, sino como puesta en abismo de la historia que quiere contar. Por otra parte, una vez más apela a la truculencia, al sensacionalismo cargado de sexo y muerte, y a un montaje heterogéneo y discontinuo. En 1983, Valencio

\footnotetext{
Valencio creó la cinemateca de Curitiba en 1975, junto a Francisco Alves dos Santos.

2 Se puede consultar en: https://www.youtube.com/watch?v=vJf4rQvabfg.

3 Se puede consultar en: https://www.youtube.com/watch?v=v4DiId9CvhI.

4 Se puede consultar en: https://www.youtube.com/watch?v=U335zoTCyQM.
} 
dirige una adaptación muy libre del cuento El cuervo, de Edgar Allan Poe. ${ }^{5}$ En 1994 filma O pão negro - Um episódio da Colônia Cecília (1994), ${ }^{6}$ basado en textos del anarquista Giovanni Rossi, fundador de la Colonia Cecilia, en el sur de Brasil. Un año después estrena Os onze de Curitiba - Todos $n o s,{ }^{7}$ que cuenta la historia de once personas encarceladas en 1978, acusadas de enseñar marxismo en guarderías y jardines de infantes. Su último filme será Nascimento, vida, paixão e morte de Cristo, realizado en $1996 .^{8}$ La particularidad de esta película es que quien hace de Jesús es un líder religioso llamado Inri Cristo, que cree ser una reencarnación de Cristo. El filme se compone de imágenes de Inri Cristo durante sus sermones en el centro de Curitiba, siendo escuchado y abucheado, y fragmentos de otros filmes sobre Jesús rodados en los comienzos del cine.

En ese lapso como cineasta, o sea entre 1976 y $1996,{ }^{9}$ Valencio publica, además del mencionado libro en colaboración con Poty Lazzarotto, una serie de textos de difícil clasificación. En 1981 edita el que será su libro más recordado, O mez da grippe, y dos años más tarde, Maciste no inferno. Entre 1985 y 1986 lanza $O$ minotauro y $O$ mistério da prostituta japonesa d Mimi-Nashi-Oichi. ${ }^{10} \mathrm{O}$ mez da grippe narra la epidemia de gripe española acontecida en Curitiba en 1918 y está construido con recortes de diarios, reproducciones de postales, fotografías y publicidades. En esta novela (por llamar al texto de algún modo) aparecerá un personaje recurrente, un sujeto solitario, voyeur, aficionado a las prostitutas, manipulador, violador y en algunos casos violento, inspirado, sin dudas, en la prensa sensacionalista. Ese personaje, sin nombre, que tiene conexiones con el protagonista de su primer corto, reaparecerá en Maciste no inferno, estructurada a partir del montaje entre fotogramas del famoso personaje del cine italiano y breves textos que narran el acoso de un hombre a una mujer que está viendo la película de Maciste que proyectan en el cine.

5 Se puede consultar en: https://www.youtube.com/watch?v=VkGsBbvgofQ\&index=11\&list= PLkmNykijK8vlep7P0MrByn8V_-d2qrUdT.

$6 \quad$ Se puede consultar en: https://www.youtube.com/watch? p $_{\mathrm{v}}=3$ 3W9jiKyDiY.

7 Se puede consultar en: https://www.youtube.com/watch?v=XYfpfWz3Jog.

8 Se puede consultar en: https://www.youtube.com/watch? $v=$ eFfyn0xsN8g.

9 Valencio Xavier continúa publicando. Su último libro es Crimes à Moda Antiga (2004).

10 Todos tienen escasa o nula repercusión debido a la radicalidad de la composición y a que son editados por editoriales pequeñas. Recién en 1998 Valencio comienza a ganar reconocimiento al ser editado por una de las editoriales más importantes de Brasil: Companhia das letras. 
¿Qué tipo de préstamos es posible pensar en este periodo entre su cine y su literatura? ¿Principios constructivos, temáticas, personajes? ¿Qué figura de autor va configurando Valencio en ese entre-lugar hecho de imágenes y palabras? ¿Un escritor que hizo cine, un cineasta que hizo literatura, o una figura indefinible, una suerte de escriteasta? Quiero ensayar un ingreso transversal a través de su producción como crítico de cine para pensar en algunas de estas cuestiones.

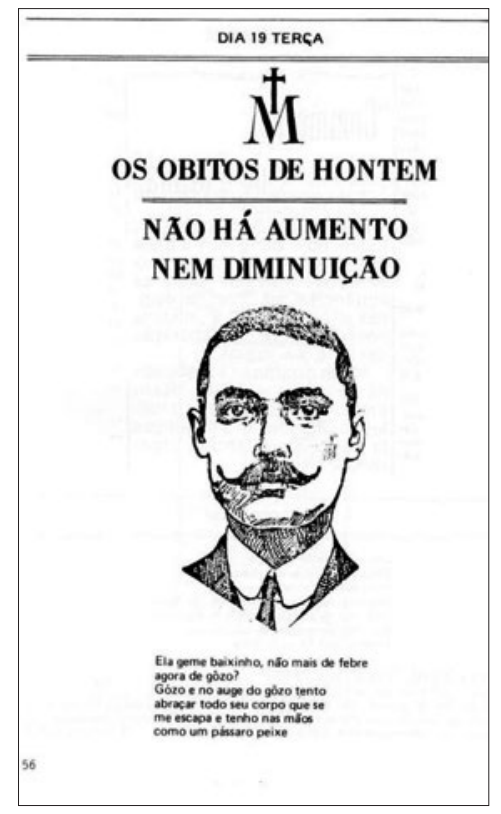

Figura 1. Detalle de $O$ mez da grippe

Fuente: Xavier, Valencio. O mez da grippe. Curitiba: Casa Romário Martins, 1981. Impreso.

\section{Historias del cine}

En 1995 se celebró el centenario de la invención del cine. Entre los muchos recordatorios, algunos de ellos célebres como las Historia(s) del cine de Jean-Luc Godard, Valencio Xavier publicó en el diario Gazeta do Povo su propio homenaje a través de una serie de pequeños textos dedicados a 100 filmes. Con un criterio entre temático y genérico, sus estampas fueron apareciendo entre agosto y diciembre de aquel año. Ese conjunto de textos serían algo así como los cien filmes que hicieron historia y que nadie debería dejar de ver. 
Los comentarios son breves, rigurosos en su extensión, quince o dieciséis líneas en todos los casos. Sin embargo, para un lector de la producción literaria de Valencio Xavier, para el lector de los mencionados $\mathrm{O}$ mez da grippe o de $\mathrm{Ma}$ ciste no inferno, o aun para quien haya visto sus ya referidos cortos, como O corvo (1983) o Caro signore Fellini (1979), todos ellos representativos de un universo circense o bajo y abyecto, los textos destinados al cine parecen escritos por un autor diferente. El lector de sus ficciones esperaría encontrar otra selección de filmes, más encuadrados dentro de la categoría de "malditos" o "bizarros". Y aunque figura un número considerable de ese tipo, que naturalmente serían considerados más próximos a su estética, como por ejemplo Freaks, La mujer pantera, Los vampiros, Cabeza borradora o La hechicería a través de los tiempos, también, entre los cien seleccionados, están La máscara o La diligencia. Esa amplitud es, en principio, desconcertante, con presencias sorprendentes y ausencias que cuesta explicar. Y si los homenajes realizados al cine en su centenario implicaban una definición de lo que había sido y era el cine, de su papel histórico y/o social, de lo que significó como arte, al final del recorrido por los filmes escogidos por Valencio, nos preguntamos un poco perplejos, ¿cuál es su idea del cine?, ¿qué representa para él?, ¿qué es lo que busca y espera?

Una primera pista importante es que Valencio no se refiere del mismo modo a los cien filmes seleccionados. En algunos casos se limita a una descripción de la trama del filme, sin involucrarse demasiado, salvo algún que otro elogio suelto en el texto. ${ }^{11}$ En otros, sus textos contienen incluso alguna referencia negativa o, al menos, ambigua: Imperio de Andy Warhol; 2001: Una odisea en el espacio, de Stanley Kubrick, o Lo que el viento se llevó, por dar algunos ejemplos. Sobre Imperio sostiene:

Em Empire, como na vida, a ação é o lento transcorrer do tempo. O tempo é o personagem num cenário único: o céu da cidade com seu (então)maior edifício destacando-se. Você perguntará: "Tudo bem, concordo, mas a emoção?". Não tem um filme que transmitir alguma emoção, um sentimento, um interesse ao espectador? O diretor do Empire diz o que sente em relação ao seu filme: "Uma ereção de oito horas!" Sei lá! Coisas do pós-modernismo de Andy Warhol". (Citado en Salete Borba 13) ${ }^{12}$

11 Todos los textos citados de Valencio Xavier fueron compilados por María Salete Borba, quien se encuentra preparando una edición de los mismos, y que me los ha cedido gentilmente para la escritura de este artículo.

12 De 2001: una odisea en el espacio afirma: "O que quis dizer Stanley Kubrick com essa parábola espacial rica em efeitos espaciais, lançada na época da rebeldia dos jovens, do 
Los filmes que más le gustan se destacan, en cambio, por la adjetivación utilizada. En los siguientes, por ejemplo, usa la categoría de obra prima: Sed de mal, de Orson Welles; La diligencia, de John Ford; Zelig, de Woody Allen; Nanook, el esquimal, de Robert Flaherty; El mensajero del miedo, de Charles Laughton; Iván el terrible, de Sergei Eisenstein; Los vampiros, de Louis Feuillade; TV Dante, de Peter Greenaway; La tierra, de Alexander Dovzhenko; La caja de Pandora, de GW Pabst; Freaks, de Tod Browning; El diablo nunca duerme, de Leo McCarey; La máscara, de Charles Russell; Lola Montes, de Max Ophüls; Cinema Paradiso, de Giuseppe Tornatore; El ladrón de Bagdad, de Michael Powell; El estigma del arroyo, de Robert Wise; La linterna roja, de Zhang Yimou; Cero en conducta, de Jean Vigo; Gerald McBoing Boing, de Robert Cannon, y Madre fuana de los Ángeles, de Jerzy Kawalerowicz. Obra prima, sin embargo, no es la única categoría clave para medir su entusiasmo. Para otros filmes, algunos de Charlie Chaplin, los primeros de Jean-Luc Godard, al menos tres de Carl T. Dreyer, Y la nave va, de Federico Fellini, y Dios y el diablo en la tierra del sol, de Glauber Rocha, propone definiciones tales como "innovación radical", "precursores" u "obras singulares". Se trata, en total, de un conjunto de entre 35 y 40 filmes que, pese a todo, continúan siendo heterogéneos entre sí. Provienen de diversas cinematografías, han sido filmados en diferentes periodos históricos y con estéticas muy disímiles.

Pero si el listado es heterogéneo, sí se detectan ausencias impactantes como la del neorrealismo italiano $;^{13}$ ihay, pese a ello, alguna conexión entre todos los filmes mencionados que hace que sean estos y no otros los verdaderamente apreciados por Valencio? ¿Qué tipo de conexión pensar? Una lectura que prescinda de las particularidades genéricas o nacionales

movimento hippie, das drogas, da guerra do Vietnã? (15-16); y de Lo que el viento se llevó nos dice: "O roteiro de Sidney Howard explora muito bem os conflitos da novela de Margareth Mitchell. Os três bons diretores que passaram pelo filme, Victor Fleming, George Cukor, Sam Wood deixaram suas marcas. A direção de arte de William Cameron Menzies jogando com o contraste de luz e cor entre os interiores e os exteriores bem explorados pela fotografia em tecnicolor, dá o clima das cenas e cria algumas das mais belas imagens do cinema. A tomada em grua partindo do close de Scarlett até mostrá-la, do alto, entre centenas de soldados feridos é comovente e inesquecível. Apesar disso, Chaplin dizia: 'Com apenas alguns closes de poucos corpos, Griffith conseguiu o mesmo efeito em El nacimiento de una nación"' (23-24).

13 La única excepción es Ladrón de bicicletas de Vittorio de Sica, al que sitúa entre los diez mejores filmes de los últimos cien años. 
encontrará dos características constantemente resaltadas: destreza técnica (sin embargo, no cualquier destreza) y producción de emoción (pero no de cualquier emoción). Y esas dos características siempre deben estar integradas, en caso contrario, se correría el riesgo de caer en un mero formalismo o en una superficial y lacrimógena historia. Y aunque parezca una tautología se puede afirmar que a Valencio le interesa un cine que trabaje con recursos puramente cinematográficos, es decir, un cine que ha abandonado sus deudas primeras con el teatro y la literatura, que ha inventado y desarrollado sus recursos técnicos y que hace un uso exhaustivo de ellos a la hora de filmar y en la sala de montaje, que ha producido un tipo específico de actuación, y que ha podido construir un lenguaje visual propio compuesto de una gramática poblada por primeros planos, contraplanos, profundidades de campo, planos secuencia, entre otros. Es decir, lo contrario de poner una cámara fija delante de un conjunto de actores para que se muevan e interactúen. Y en tanto este conjunto de técnicas constituye el cine, es que Valencio puede prescindir de un gusto orientado a un determinado género o cinematografía. Parte de su pluralidad se encuentra en una apreciación de la técnica cinematográfica.

Para Valencio, el cine no solo es la antítesis del teatro, sino, quizá más profundamente, lo es también de la literatura. Cuando la literatura invade al cine, lo destituye. El cine debe operar una reducción a cero de cualquier psicologismo porque uno de sus rasgos esenciales es la acción. Y la acción es movimiento. En este sentido, si algo distingue al cine de otras artes visuales como la fotografía y la pintura, es que propone imágenes en movimiento. ${ }^{14}$ Pero no se trata de cualquier tipo de movilidad. Es decir, sin movimiento no hay cine, pero no todo movimiento es cine. Las imágenes en movimiento que considera adecuadas son el resultado de una composición por medios visuales (montaje, encuadre, iluminación) y sonoros (banda de sonido, ruidos). Siempre es coreografía, disposición de cuerpos y objetos de manera intencionada. A Valencio, por lo tanto, le interesa un cine de la puesta en escena tal como lo entendió la generación nouvelle vague en relación a ciertos directores de Hollywood como

14 Esto se puede pensar en relación al concepto que crea Deleuze de "imagen-movimiento": "El cine procede con fotogramas, es decir con cortes inmóviles, veinticuatro imágenes por segundo (o dieciocho, al comienzo). Pero lo que nos da, y esto se observó con frecuencia, no es el fotograma, sino una imagen media a la que el movimiento no se añade, no se suma: por el contrario, el movimiento pertenece a la imagen media como dato inmediato" (15). 
Alfred Hitchcock, Howard Hawks, John Ford, Fritz Lang y Orson Welles. "La noción de puesta en escena que circula en esos años es dialéctica. Lo central es la forma de llevar a cabo una historia (posición de la cámara, iluminación, dirección de actores, montaje, etc.)" (51), nos recuerda Domin Choi en relación a los nouvelle vague.

Si Valencio se aproxima a los nouvelle vague en la concepción de la puesta en escena, se distancia de lo que podríamos definir como cierta ética baziniana de lo filmable, central para esta generación. Para los nouvelle vague lo filmable, en una tradición que André Bazin hacía nacer en el neorrealismo italiano, no por casualidad ausente en la selección de Valencio, era el acontecimiento producido en el rodaje. Para Valencio, en cambio, el acontecimiento es resultado de la puesta en escena, y esta lo es del cálculo del director. ${ }^{15} \mathrm{El}$ cine es un arte en el que nada debe ser librado al azar. A diferencia de la famosa máxima de Rossellini, "las cosas están ahí, cipor qué manipularlas?" (citado en Ismail Xavier 99), ${ }^{16}$ Valencio sostiene que "en el cine el hábito hace al monje". ${ }^{17}$ Para Rossellini, y también para Bazin, el cine nos revela lo real si la cámara sabe cómo captarlo. $\mathrm{El}$ acontecimiento se encuentra allí para ser capturado por el dispositivo técnico; para Valencio, en cambio, lo que este atrapa primero debe ser producido en el set de filmación y en la sala de montaje. ${ }^{18}$

Su concepción de la puesta en escena no debe ser pensada en términos formales, pues siempre debe estar en función de algo, y ese algo, es la emoción del espectador, que viene a constituir la otra faceta de la esencia del cine. La emoción como resultado de la puesta en escena también le permite a Valencio no encasillarse en un género o cinematografía determinada. Acción y emoción en función de un espectador.

15 Es interesante señalar que tanto Bazin como Valencio, aunque desde un enfoque diferente, se ocupan de Orson Welles. A Bazin le interesa el trabajo de Welles con el plano secuencia, mientras que a Valencio le interesa más el trabajo con el montaje que hace Welles.

16 La cita completa es "El montaje no es más esencial. Las cosas están ahí, y sobra en este filme. ¿Por qué manipularlas?" (citado en Ismail Xavier 99). Se refería a su filme India (1959).

17 Para referirse a Rua da paz, de Chaplin, Valencio sostiene: "Carlitos é o personagem mais consistente e, portanto, o mais célebro do cinema. Ao contrário do ditado, no cinema o hábito faz o monge" (42).

18 En relación a Bazin y su concepción del cine, Ismail Xavier sostiene: "cabe al cine mantenerse fiel a su dimensión 'ontológica': testimoniar una existencia, respetarla en sí misma y dejar de este modo que ella revele lo que ella tiene de esencial" (110). 
La emoción actúa como el equivalente del acontecimiento baziniano, o de la necesidad de "atrapar" al espectador que reclamaba Eisenstein para el cine soviético. Sin embargo, ¿cómo es posible la emoción si todo está calibrado a través de la puesta en escena? Precisamente es esta la única capaz de garantizar una emoción genuina y verdadera. Por ello, la emoción, que es lo mismo que decir afecto, ${ }^{19}$ es resultado, en principio, de una capacidad constructiva, luego del adecuado énfasis dado a esa construcción con el objetivo de hacer ver y transmitir un determinado sentimiento, cualquiera que este sea, al espectador.

La intriga, el suspenso, el miedo, la simpatía y toda la gama de afectos que puede generar una película se producen no en el guion, ni en alguna obra literaria que sirva de fuente, sino en el manejo de cámara y en el montaje. Por eso, Orson Welles puede tomar "um mediocre romance policial" 20 y filmar Sed de mal, cuyo comienzo describe de la siguiente manera:

O filme começa com um longo plano-sequência de 3 minutos: na noite, detalhe de mão acionando uma bomba-relógio, a câmera se afasta $\mathrm{e}$ mostra um homem colocando a bomba num carro, e fugindo para não ser visto por um casal que chega. A câmera, numa grua, sobe e mostra o carro na rua de uma cidadezinha da fronteira Estados Unidos-México, desce e acompanha um casal que caminha na calçada, emparelhado com o carro do outro casal. Chegam na aduana, os guardas reconhecem o policial mexicano e sua esposa americana, falam sobre Vargas estar investigando traficantes de drogas. O casal do carro é liberado também, a moça queixa-se de ouvir um tique-taque. A câmera está com Vargas e sua esposa; são recém-casados, enquanto se beijam ouvem a explosão do carro que passou por eles. (14)

En tal sentido, el cine para Valencio no es representación de la realidad, ni de lo imaginario, es una máquina de producir emocionesafectos-afecciones. El verdadero cine, y es aquí donde se distingue su ética cinematográfica, debe ser capaz de producir figuras visuales, tramas enteras, en torno a las pasiones humanas a través de una gramática afectiva generada por el montaje y el manejo de la cámara. No es casual que,

19 Es lo mismo en el sentido en que el espectador es afectado por la historia que está viendo.

20 La novela en la que se basa Orson Welles se llama Badge of Evil, escrita por Whit Masterson.

Y, en otro comentario, aunque no va a definir la novela $O$ ano passado em Marienbad, de Alain Robbe-Grillet, como mediocre, le va a otorgar a Alain Resnais la capacidad de reinventar la historia de modo puramente cinematográfico. 
en su primer texto, dedicado a La llegada del tren de Lumière, Valencio destaque la emoción que produjo aquella proyección en los asistentes, y que cuando escriba sobre Imperio, de Andy Warhol, se pregunte, "¿tudo bem, concordo, mas a emoção?" (13). Por ello, cuando se refiere al uso de la cámara en Napoleón de Abel Gance, destaca su uso en función de transmitir emociones. ${ }^{21}$

Sostener esta posición supone una determinada creencia en la potencia de la ficción. En este sentido, y en relación al montaje, el pensamiento de Valencio está más próximo al de realizadores como Lev Kuleshov, para quien no solo lo específicamente cinematográfico es el momento de la organización del material filmado, sino que la yuxtaposición de planos puede expresar lo que estos tienen de esencial al producir un significado de conjunto; ${ }^{22}$ o más cercano al de Serguei Eisenstein, que denominó "montaje de atracciones" al procedimiento destinado a romper con el ilusionismo naturalista. "La atracción [...] es todo momento agresivo en él, es decir todo elemento que despierte en el espectador aquellos sentidos o aquella psicología que influyen en sus sensaciones, todo elemento que pueda ser comprobado y matemáticamente calculado para producir ciertos choques emotivos en un orden adecuado dentro de un conjunto" (172). Aunque también, sin dudas, se interesa por el montaje a la Griffith, de quien reseña dos de sus filmes, y a quien destaca como uno de los grandes directores de todos los tiempos. De O nascimento de uma Nação, por ejemplo, sostiene:

Griffith absorbe os avanços feitos por Méliès e Porter na linguagem cinematográfica e, com seu talento, desenvolve-os. Filma as cenas alternando os planos, dando ritmo e fluência na montagem. Nos filmes da época todas as cenas eram rodadas num único plano, uma visão teatral. Não foi o primeiro a usar o close, mas foi o primeiro a usá-lo com função narrativa [...]. O nascimento de uma nação fez grande sucesso. Acusado

21 Dice Valencio: "Para traçar sua visão de Napoleão, Abel Gance parte para o exagero da imagem. Fixa a câmera no peito de um tenor para dar sua visão, e emoção, dos deputados ouvindo-o cantar a Marsellesa. A câmera montada num cavalo para dar a visão do galope" (84).

22 Véase Lev Kuleshov (1961). Según Kuleshov, el plano es un signo que se engarza con otro signo en el montaje. Una aclaración importante, para Kuleshov, el montaje debe producir una narración perfectamente fluida; para Valencio, más que la fluidez, lo importante es la emoción que produce el montaje, sea este continuo y fluido o discontinuo. 
de racista, foi boicotado em vários lugares, mas com ele o cinema atinge a maioridade e está pronto para seu desenvolvimento posterior. ${ }^{23}$

Ética de lo filmable, y potencia de la ficción para construir la verdad de las emociones/afecciones. El cine es un dispositivo que produce imágenes que no reproducen el mundo, sino afecciones y sensaciones en el espectador $(20) \cdot{ }^{24}$

\section{Gestos}

Un epígrafe enigmático con el que abre su novela más famosa, $O$ mez $d a$ grippe, describe a la perfección esa confianza:

Vê-se um sepulcro cheio de cadáveres, sobre os quais se podem observar todos os diferentes estados da dissolução, desde o instante da morte até a destruição total do indivíduo. Esta macabra execução é de cera, colorida com tanta naturalidade que a natureza não poderia ser, nem mais expressiva, nem mais verdadeira. Marquês de Sade. $(5)^{25}$

El epígrafe transcripto funciona como un manifiesto de su proyecto literario y de su visión sobre el cine. La ficción -sea esta cinematográfica o literaria- a través de sus encadenamientos expresa una verdad siempre más potente que cualquier imagen o palabra de la realidad, que afecta al espectador y al lector. Pero solo una imagen verdadera, es decir, obtenida en una rigurosa puesta en escena, es capaz de producir una afección genuina. Su predilección por un concepto fuerte de puesta en escena y por un montaje que produce afecciones no solo define el cine que le interesa a Valencio, son los principios con los que ha compuesto su literatura. Valencio utiliza el montaje en Mimi-Nashi-Oichi a través del uso de citas ensambladas; Maciste no inferno está construido con fotogramas del filme homónimo, ${ }^{26}$ breves recuentos de su historia, y la narración del personaje que ingresa al cine; en $O$ minotauro el montaje se produce a partir de la

23 Y de Intolerancia afirma: "Nunca antes um filme ousara tanto" (31).

24 Las imágenes siempre están destinadas a un espectador.

25 El epígrafe pertenece a Diário do mez da gripe. Por otra parte, el epígrafe de 13 mistérios mas $O$ mistério da porta aberta es igualmente revelador: "Uma mentira minha vale por dez verdades tuas. Dito por um criminoso no programa de Algaci Túlio" (O mez da grippe e outros livros, 205).

26 El nombre Maciste corresponde a un personaje menor de la mitología griega, hijo de Atamante. En el cine italiano gozó de gran éxito y fue representado, al igual que otros personajes como 
relación aleatoriamente ensamblada entre narración y numeración; en $O$ mez da grippe, el texto más explícitamente montado de su producción, las páginas contienen narraciones en primera y en tercera persona, recortes de diarios, discursos estatales, cartones postales.

Pero, ¿cuál es el objetivo de esos montajes? El más visible consiste en producir discontinuidades espaciales y temporales en el material narrativo que nos presenta, acentuadas por los materiales lingüísticos y visuales (fotografías, fotogramas, tarjetas postales, recortes de diario) con los que trabaja. Esas discontinuidades, a su vez, procuran motivar al lector a construir una lectura crítica de los materiales en función de su proximidad. Pero hay otros dos objetivos que se deben apuntar, más ligados a la idea de emoción y afecto que le interesa en el cine. Uno consiste en crear zonas de incertidumbre y eso se percibe claramente en los testimonios contrapuestos de $O \mathrm{mez}$ da gripe o en los recorridos del personaje de $O$ minotauro, por dar dos ejemplos; el otro apunta a producir narrativas pulsionales, presentes casi en todos sus textos, desde $O$ mez da gripe hasta $O$ misterio da prostituta. Ambos, zonas de incertidumbre y narrativas pulsionales, parecen poner en tensión la puesta en escena literaria cuidadosamente montada.

El sexo como pulsión clandestina, solitaria y, frecuentemente, descontrolada; y la muerte como evento violento y no calculado componen las narrativas pulsionales, ${ }^{27}$ mientras que las interferencias del sentido, los desafíos a los intentos del lector por recomponer una linealidad -ya quebrada por el dispositivo del montaje- conforman las zonas de incertidumbre. Estos dos elementos son puestos a funcionar en relatos cuyo protocolo de lectura siempre es el realismo, y que al contaminarlos producen la emanación de sentidos inesperados a partir de situaciones o escenarios que en principio fueron presentados bajo el ropaje de la familiaridad. Algunas de sus narraciones podrían ser pensadas como el relato de un sueño vivido con el máximo realismo, pero en el que suceden situaciones que nos sorprenderían en la vigilia, por ejemplo, en $O$ misterio da prostituta japonesa, en la que la prostituta le habla en japonés a su cliente, y este no solo acepta la situación, sino que parece comprender perfectamente de qué está hablando la mujer.

Hércules o Ursus, como un ser bondadoso que lucha por el desprotegido por medio de su fuerza sobrehumana.

27 El epígrafe de Sade también debe ser leído, en este sentido, como una cita que revela un diálogo, una afinidad con el autor francés. 
Por ello, uno de los afectos que construye y transmite su literatura es el de la inquietud. Sin dudas, lo que persigue Valencio en sus textos es la creación de un siniestro literario que induzca al lector -angustiándolo- a construir interpretaciones para hacer encajar en la trama los cabos sueltos que astutamente disemina en sus narraciones. Y otro aspecto importante es que este siniestro literario lo construye, en gran medida, con materiales de la industria cultural: prensa amarilla, crímenes sin resolución, casos aparentemente inexplicables, rumores. En este sentido, Jorge Wolff lo ha definido como "um saqueador contumaz da cultura do espetáculo" (240), especialmente de sus aristas más sexualizadas y violentas.

Sus breves textos sobre cine, podemos concluir, permiten reimaginar una figura de autor que subsuma cine y literatura. Proponer, en primer lugar, el concepto de puesta en escena literaria para pensar sus relatos matemáticamente calculados a efectos de producir una desfamiliarización, y también el de gesto cinematográfico, que permitiría evitar la idea de influencia -del cine sobre la literatura-, de hibridez -el cine y la literatura como lenguajes que se cruzan-, enfatizando la idea de potencias de la ficción que Valencio persigue en el cine, la literatura y las artes en general.

\section{Obras citadas}

Choi, Domin. Transiciones del cine. De lo moderno a lo contemporáneo.

Buenos Aires: Santiago Arcos, 2009. Impreso.

Deleuze, Gilles. La imagen-movimiento. Barcelona: Paidós, 1984. Impreso.

Eisenstein, Serguei. El sentido del cine. México: Siglo XXI editores, 2010. Impreso.

Kuleshov, Lev. Tratado de realización cinematográfica.

Buenos Aires: Futuro, 1961. Impreso.

Salete Borba, María, comp. 100 anos em 100 filmes. Mimeo.

Xavier, Ismail. El discurso cinematográfico. La opacidad y la transparencia. Buenos Aires: Manantial, 2008. Impreso.

Xavier, Valencio. O mez da grippe. Curitiba: Casa Romário Martins, 1981. Impreso.

Xavier, Valencio. O mez da grippe e outros livros. São Paulo: Companhia das Letras, 1998. Impreso.

Wolff,Jorge. "Valêncio Xavier: o autor como profanador". O futuro pelo retrovisor. Org. Stefania Chiarelli, Giovanna Dealtry y Paloma Vidal. Rio de Janeiro: Rocco, 2013. Impreso. 